Research article

Open Access

\title{
Akt kinases in breast cancer and the results of adjuvant therapy
}

Olle Stål ${ }^{1}$, Gizeh Pérez-Tenorio ${ }^{1}$, Linda Åkerberg ${ }^{1}$, Birgit Olsson ${ }^{1}$, Bo Nordenskjöld ${ }^{1}$, Lambert Skoog ${ }^{2}$ and Lars Erik Rutqvist ${ }^{3}$

\author{
${ }^{1}$ Department of Biomedicine and Surgery, Division of Oncology, Faculty of Health Sciences, Linköping University, Linköping, Sweden \\ ${ }^{2}$ Division of Cytology, Karolinska Hospital, Stockholm, Sweden \\ ${ }^{3}$ Department of Oncology, Huddinge University Hospital, Stockholm, Sweden \\ Corresponding author: Olle Stål (e-mail: olle.stal@onk.liu.se)
}

Received: 1 August 2002 Revisions received: 22 November 2002 Accepted: 16 December 2002 Published: 20 January 2003

Breast Cancer Res 2003, 5:R37-R44 (DOI 10.1186/bcr569)

(C) 2003 Stål et al., licensee BioMed Central Ltd (Print ISSN 1465-5411; Online ISSN 1465-542X). This is an Open Access article: verbatim copying and redistribution of this article are permitted in all media for any non-commercial purpose, provided this notice is preserved along with the article's original URL.

\begin{abstract}
Background: The serine/threonine kinase Akt, or protein kinase $B$, has recently been a focus of interest because of its activity to inhibit apoptosis. It mediates cell survival by acting as a transducer of signals from growth factor receptors that activate phosphatidylinositol 3-kinase.
\end{abstract}

Methods: We analysed the expression of the isoforms Akt1 and Akt2 as well as phosphorylated Akt (pAkt) by immunohistochemistry in frozen tumour samples from 280 postmenopausal patients who participated in a randomised trial comparing cyclophosphamide-methotrexate-5-fluorouracil chemotherapy and postoperative radiotherapy. The patients were simultaneously randomised to tamoxifen or to no endocrine treatment.

Results: Marked staining was found in $24 \%$ of the tumours for Akt1, but in only 4\% for Akt2. A low frequency of Akt2-positive cells $(1-10 \%)$ was observed in another $26 \%$ of the tumours. pAkt was significantly associated with both Akt1 and Akt2 expression. Overexpression of erbB2 correlated significantly with pAkt $(P=0.0028)$. The benefit from tamoxifen was analysed in oestrogen receptor (ER)-positive patients. Patients with a negative status of Akt (no overexpression of Akt1, Akt2 or pAkt) showed significant benefit from tamoxifen. The relative rate of distant recurrence, with versus without tamoxifen, was 0.44 (95\% confidence interval [Cl], 0.25-0.79) for ER+/Akt1patients, while it was $0.72(95 \% \mathrm{Cl}, 0.34-1.53)$ for ER+/Akt1+ patients. The difference in rate ratio did not reach statistical significance. The rate of locoregional recurrence was significantly decreased with radiotherapy versus chemotherapy for Akt-negative patients (rate ratio, $0.23 ; 95 \% \mathrm{Cl}, 0.08-0.67$; $P=0.0074$ ), while no benefit was evident for the Akt-positive subgroup (rate ratio, $0.77 ; 95 \% \mathrm{Cl}, 0.31-1.9 ; P=0.58$ ). The interaction between Akt and the efficacy of radiotherapy was significant in multivariate analysis $(P=0.042)$.

Conclusion: Activation of the Akt pathway is correlated with erbB2 overexpression in breast cancer. The results suggest that Akt may predict the local control benefit from radiotherapy.

Keywords: erbB2, HER-2/neu, protein kinase B, radiotherapy, tamoxifen, treatment outcome

\section{Introduction}

The regulation of cell proliferation and cell survival in breast cancer is a complex interplay between steroid hormones, growth factors and their receptors. The understanding of the signalling pathways involved in these processes may help us find predictive factors for tumour aggressiveness and therapy resistance. Already recognised is the importance of the oestrogen receptor (ER) status of the tumour for predicting the benefit from endocrine treatment [1].

Although it has not yet been fully established from clinical materials, experimental studies suggest that overexpression of different growth factor receptors in breast cancer makes cells less sensitive to tamoxifen and other cytotoxic drugs. These receptors include insulin-like growth factor

$\mathrm{Cl}=$ confidence interval; $\mathrm{CMF}=$ cyclophosphamide-methotrexate-5-fluorouracil; $\mathrm{ER}=$ oestrogen receptor; FITC = fluorescein isothiocyanate; pAkt = phosphorylated Akt; PI3-K = phosphatidylinositol 3-kinase; $\mathrm{RR}=$ rate ratio. 
receptors and members of the epidermal growth factorreceptor family (reviewed in [2,3]). The receptor most analysed in breast cancer is the erbB2 receptor, also known as HER-2/neu, and its overexpression has shown prognostic significance in a number of studies (reviewed in [4]). The growth factor receptors utilise several signalling pathways, such as the ras/mitogen-activated protein kinase pathway that is important for mitogenic stimulation. Other receptor signals are transmitted by the phosphatidylinositol 3-kinase (PI3-K)/Akt pathway. The activation of this pathway has proven important for cell survival, and inhibitors have been shown to facilitate apoptosis and to sensitise cells to cytotoxic drugs in experimental studies [5-8]. Proteins that participate in this signalling might therefore be good candidates for predicting the result of therapy.

The serine/threonine kinase Akt, or protein kinase $B$, is a downstream effector of PI3-K. Akt is important in mediating several metabolic actions of insulin, while another major activity is to mediate cell survival [5,9-11]. Among several mechanisms, Akt inhibits apoptosis by phosphorylating the Bcl-2 family member Bad and by preventing the release of cytochrome $c$ from mitochondria [12-14]. Overexpression of Akt therefore may contribute to tumour development and progression. This is further supported by the tumour suppressor PTEN, which is frequently mutated or deleted in a large number of human cancers, inactivating the PI3-K/Akt pathway [15-18].

Akt1, Akt2 and Akt3 are three isoforms with high sequence homology encoded by three separate genes [19-21]. Akt1 is the predominant isoform in most tissues, whereas the highest expression of Akt2 has been observed in the insulin-responsive tissues [22]. Amplification of the Akt2 gene has been found in some cases of ovarian cancer, breast cancer and pancreatic cancer [23-25].

In the present study we have analysed Akt1 and Akt2 protein expression as well as Akt phosphorylated at serine 473 (pAkt) in tumour samples from 280 postmenopausal breast cancer patients. These patients participated in a randomised trial comparing adjuvant cyclophosphamidemethotrexate-5-fluorouracil (CMF) chemotherapy and postoperative radiotherapy. The patients were simultaneously randomised to tamoxifen or to no endocrine treatment.

\section{Materials and methods Patients}

In 1976 the Stockholm Breast Cancer Group initiated a trial to compare postoperative radiotherapy with adjuvant chemotherapy [26]. The trial included premenopausal and postmenopausal patients with a unilateral, operable breast cancer. Using a $2 \times 2$ factorial study design, the post-
Table 1

The number of patients allocated to different adjuvant therapies

\begin{tabular}{lcc}
\hline & No tamoxifen & Tamoxifen \\
\hline Postoperative radiotherapy & 60 & 60 \\
Chemotherapy (CMF) & 82 & 78 \\
\hline
\end{tabular}

CMF, cyclophosphamide-methotrexate-5-fluorouracil.

either tamoxifen treatment or no endocrine treatment. There was thus a total of four treatment groups: adjuvant chemotherapy, adjuvant chemotherapy plus tamoxifen, radiotherapy, and radiotherapy plus tamoxifen. Tamoxifen was given postoperatively at a dose of $40 \mathrm{mg}$ daily for 2 or 5 years. Surgery consisted of modified radical mastectomy. The patients were required to have either histologically verified lymph node metastases or a tumour diameter, measured on the surgical specimen, exceeding $30 \mathrm{~mm}$. Patient accrual started in November 1976 and ended in April 1990. The current study included a subset consisting of 280 postmenopausal patients for whom frozen tumour tissue was still available after hormone receptor assays had been performed in routine practice (Table 1).

Radiotherapy was given with a high-voltage technique. The dose was 46 Gy with 2 Gy per fraction 5 days a week for a total treatment time of about 4.5 weeks. The target volume included the chest wall, the axilla, the supraclavicular fossa and the internal mammary nodes. For most of the patients randomised to chemotherapy, the treatment consisted of 12 courses of CMF according to the original Milan protocol $\left(100 \mathrm{mg} / \mathrm{m}^{2}\right.$ cyclophosphamide orally at days $1-14,40 \mathrm{mg} / \mathrm{m}^{2}$ methotrexate intravenously on days 1 and 8 , and $600 \mathrm{mg} / \mathrm{m}^{2} 5$-fluorouracil intravenously on days 1 and 8). During the first 18 months of the trial, however, cyclophosphamide was replaced by $10-15 \mathrm{mg}$ chlorambucil orally on days $1-8$, and up to 18 months was allowed for the 12 courses to avoid dose reductions. The patients were followed for a median period of 11 years. A distant recurrence was registered in 126 patients and a locoregional recurrence was registered in 48 cases.

\section{Immunohistochemistry}

The expression of Akt1, Akt2 and pAkt was analysed with immunohistochemistry. Goat polyclonal antibodies against Akt1 and Akt2 (Santa Cruz Biotechnology Inc., Santa Cruz, CA, USA), and a sheep polyclonal antibody against the phosporylated serine residue in position 473 of human Akt-1 (Upstate Biotechnology, Lake Placid, NY, USA) were used for immunostaining. The latter antibody might cross-react with other activated isoforms of Akt. In negative controls the primary antibodies were replaced by $\lg G$ immunoglobulins (Sigma Chemical Co., St Louis, MO, USA). Frozen sections of $5 \mu \mathrm{m}$ were cut from the tumours and the slides were kept frozen until they were used for 
immunohistochemistry. The sections were fixed in acetone $\left(4^{\circ} \mathrm{C}\right)$ for $10 \mathrm{~min}$. Endogenous peroxidase activity was quenched with $3 \%$ hydrogen peroxide in methanol for $5 \mathrm{~min}$, and thereafter the sections were incubated with normal swine serum (10\%) for $10 \mathrm{~min}$ in order to block nonspecific immunostaining. The specimens were then incubated with the primary antibodies $(8 \mu \mathrm{g} / \mathrm{ml}$ for Akt1 and Akt2, $1 \mu \mathrm{g} / \mathrm{ml}$ for pAkt) at room temperature for $60 \mathrm{~min}$, or overnight at $4^{\circ} \mathrm{C}(\mathrm{pAkt})$, followed by incubation with a biotinylated swine multilink antibody and streptavidin conjugated with horseradish peroxidase for $30 \mathrm{~min}$ each. The slides were finally stained with 3.3-diaminobenzidine tetrahydrochloride, counterstained with haematoxylin, dehydrated in a series of ethanols and mounted. Tumours strongly positive for the Akt kinases were used for positive controls, which were included in each batch.

The tumours were scored independently by two investigators. Tumours with clearly stained cells were further scored taking into account the frequency of immunostained malignant cells $(>10 \%$ or $<10 \%)$. The staining was not evaluated due to poor quality of the sections in eight cases for Akt1, in 10 cases for Akt2 and in six cases for pAkt.

\section{ErbB2 protein expression}

ErbB2 protein expression was quantified with an immunocytochemical method using flow cytometry as has been described elsewhere [27]. Cell suspensions were prepared by mechanical disintegration of frozen tumour tissue, filtered and were fixed in $1 \%$ paraformaldehyde for $3 \mathrm{~min}$ at room temperature. The cells were incubated either with the c-neu antibody (Ab-2, clone 9G6; Oncogene Research Products, Cambridge, MA, USA) or with lgG $_{1}$ immunoglobulins (Sigma Chemical Co.) as a control (both $0.5 \mu \mathrm{g} / \mathrm{ml}$ ). Thereafter, a secondary FITC-conjugated antibody (Dako, Glostrup, Denmark) was added. Samples were analysed with a FACSCalibur flow cytometer (Becton Dickinson, San Diego, CA, USA) equipped with a $15 \mathrm{~mW}$ argon laser for excitation of FITC. A measure of erbB2 expression was calculated from the paired samples. The cut-off threshold used for erbB2 overexpression was the same as that used in previous studies $[28,29]$.

\section{Statistical methods}

The rates of recurrence in relation to treatment and other variables were estimated and tested using Cox's proportional hazards model [30]. A test for the potential interaction between Akt and the benefit from treatment was performed by a Cox model including the covariates Akt, treatment, and the interaction term treatment $\times$ Akt. The product-limit method was used for estimation of cumulative probabilities of recurrence-free survival [31]. Relationships between grouped variables were tested by means of chi-square tests for contingency tables with ordered categories.
Table 2

The immunohistochemical score for Akt1 $(n=272)$, Akt2

$(n=270)$ and phosphorylated Akt (pAkt) $(n=274)$

\begin{tabular}{lccl}
\hline & \multicolumn{3}{c}{$\%$ immunostained cells } \\
\cline { 2 - 4 } & $0 \%$ & $1-10 \%$ & $>10 \%$ \\
\hline Akt1 & $192(70)$ & $15(6)$ & $65(24)$ \\
Akt2 & $189(70)$ & $71(26)$ & $10(4)$ \\
pAkt & $136(50)$ & $63(23)$ & $75(27)$ \\
\hline
\end{tabular}

Data presented as $n(\%)$.

\section{Results}

The results of the immunostaining for Akt1, Akt2 and pAkt are presented in Table 2. All three forms exhibited cytoplasmic staining, to some extent localised to the cell membrane (Fig. 1). The staining patterns for Akt1 and Akt2 were different. In the immunopositive tumours, Akt1 was frequently expressed in a high percentage of cells, whereas the staining of Akt2 was mostly sparse. Most normal cells were negative for the Akt kinases. However, the basal cells of ductal structures stained positive for Akt1.

Regarding positive immunostaining in more than $10 \%$ of the cells, pAkt staining was significantly associated with both Akt1 and Akt2 staining (Table 3), although the correlation was stronger for Akt1 $(P<0.001)$ than for Akt2 $(P=0.020)$. There was also a significant correlation between Akt1 and Akt2 staining $(P<0.001)$. Akt1 was not significantly associated with other tumour characteristics, including lymph node status, tumour size, ER status and erbB2. Akt2-positive tumours were more often ER-nega-

\section{Figure 1}
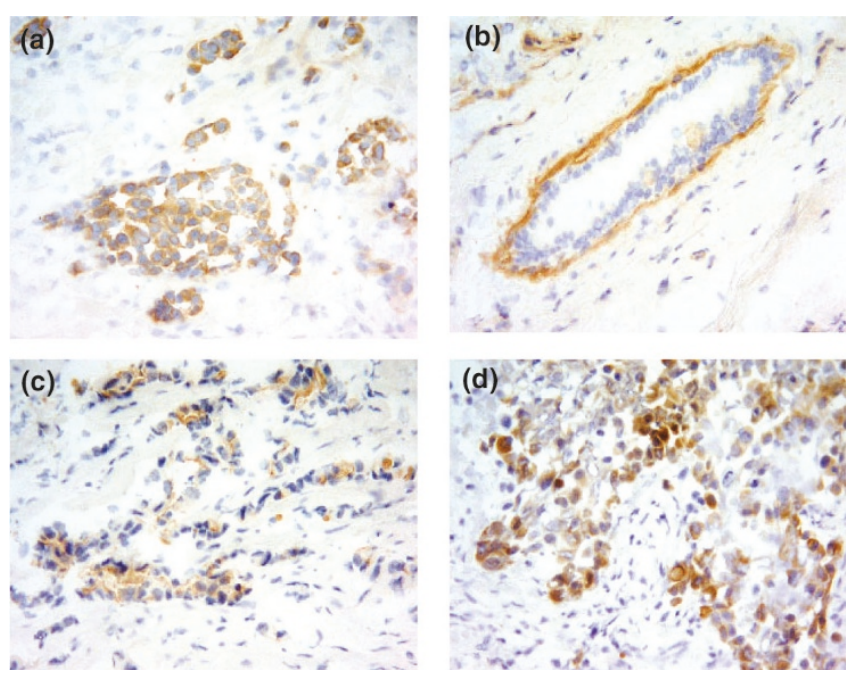

Immunostaining of (a, b) Akt1, (c) Akt2 and (d) phosphorylated Akt. 
Table 3

The interrelationship between Akt1, Akt2 and phosphorylated Akt (pAkt) immunostaining

\begin{tabular}{|c|c|c|c|c|c|c|}
\hline & \multicolumn{3}{|c|}{ Akt2 immunostaining } & \multicolumn{3}{|c|}{ pAkt immunostaining } \\
\hline & $0 \%$ & $1-10 \%$ & $>10 \%$ & $0 \%$ & $1-10 \%$ & $>10 \%$ \\
\hline \multicolumn{7}{|l|}{ Akt1 } \\
\hline 0 & $149(78)$ & $35(18)$ & $6(3)$ & $99(52)$ & $42(25)$ & $43(26)$ \\
\hline $1-10 \%$ & $9(60)$ & $6(40)$ & $0(0)$ & $10(67)$ & $3(20)$ & $2(13)$ \\
\hline$>10 \%$ & $31(48)$ & $30(46)$ & $4(6)$ & $26(40)$ & $9(14)$ & $30(46)$ \\
\hline \multicolumn{7}{|l|}{ Akt2 } \\
\hline 0 & & & & $91(48)$ & $49(26)$ & $48(26)$ \\
\hline $1-10 \%$ & & & & $40(57)$ & $10(14)$ & $20(29)$ \\
\hline$>10 \%$ & & & & $3(30)$ & $1(10)$ & $6(60)$ \\
\hline
\end{tabular}

Data presented as $n(\%)$.

tive than other tumours $(P=0.030)$. Overexpression of erbB2 was significantly associated with pAkt; $44 \%$ of the erbB2-positive tumours showed pAkt staining in more than $10 \%$ of the cells, as compared with $22 \%$ of the tumours with a negative erbB2 status $(P=0.0028)$. Tumours that simultaneously expressed Akt1 and Akt2 were more often erbB2-positive than other tumours $(P=0.040)$.

\section{The benefit from tamoxifen in relation to ER, Akt and erbB2}

The benefit from tamoxifen in terms of improved distant recurrence-free survival was restricted to ER-positive patients. The relative rate of distant recurrence comparing patients who were treated with adjuvant tamoxifen or were not was 0.56 (95\% confidence interval [Cl], 0.36-0.87) for the ER-positive group, while it was $1.3(95 \% \mathrm{Cl}$, $0.72-2.5)$ for ER-negative patients. The difference in relative rate was statistically significant $(P=0.024)$.

We next investigated a possible interaction between the expression of Akt and the benefit from tamoxifen for ERpositive patients. To increase the statistical power, patients whose tumours showed strong staining (>10\%) for either Akt1, Akt2 or pAkt were grouped together and were defined as Akt-positive. The benefit from tamoxifen was largely confined to ER+/Akt- patients (Fig. 2). In this group, adjuvant tamoxifen decreased the risk of distant recurrence by $56 \%$ (rate ratio $[R R]=0.44 ; 95 \% \mathrm{Cl}$, $0.25-0.79$ ), while the risk reduction was not statistically significant for Akt-negative patients ( $R R=0.72 ; 95 \% \mathrm{Cl}$, 0.34-1.53). The interaction between Akt and tamoxifen did not reach statistical significance in multivariate analysis that also included other tumour characteristics $(P=0.28$; Table 4). Likewise, the erbB2 status failed to predict the benefit from tamoxifen; however, the ER+/erbB2+ sub-
Figure 2
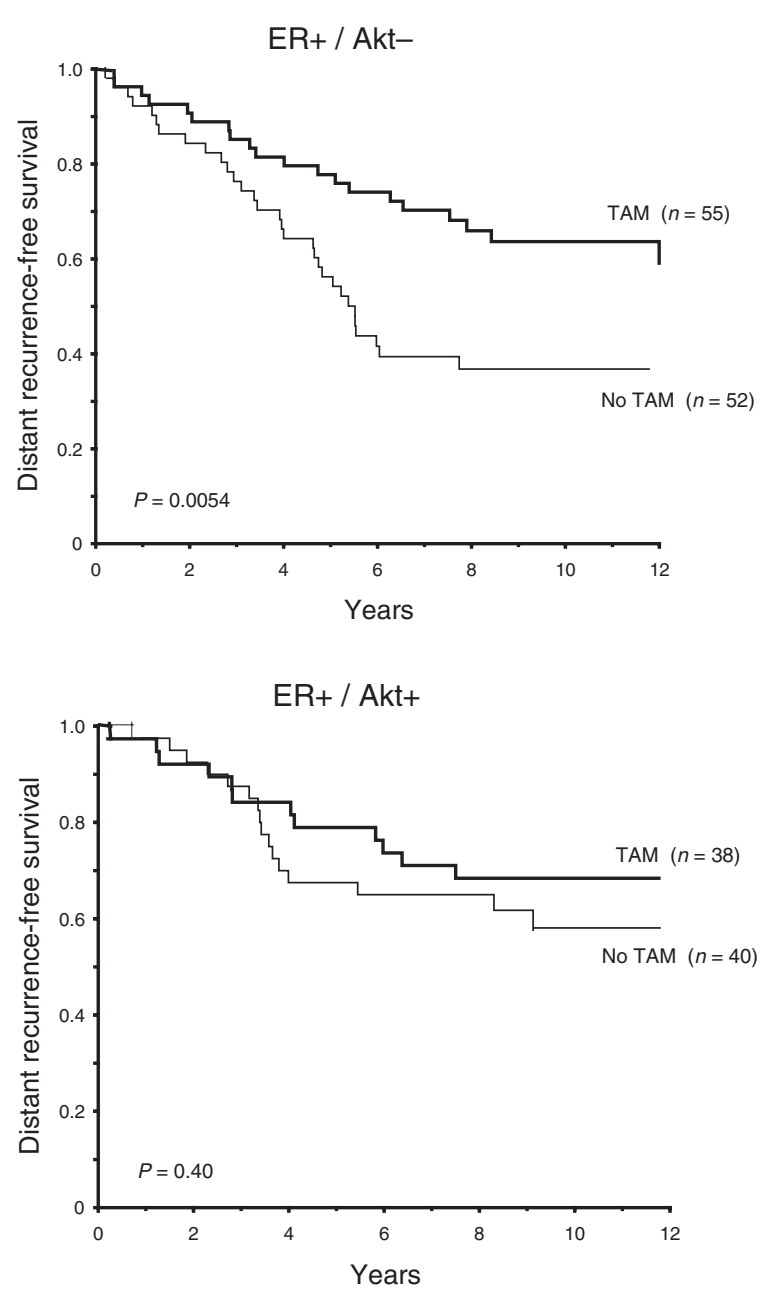

Distant recurrence-free survival for oestrogen receptor (ER)-positive patients treated with tamoxifen (TAM) or not (no TAM) in relation to Akt status. 
Table 4

\begin{tabular}{|c|c|c|c|}
\hline & $\begin{array}{l}\text { Number } \\
\text { of patients }\end{array}$ & $\begin{array}{l}\text { Rate } \\
\text { ratio }\end{array}$ & $\begin{array}{c}\text { Test for } \\
\text { significance }(P)\end{array}$ \\
\hline \multicolumn{4}{|l|}{ Number of positive nodes ${ }^{a}$} \\
\hline 0 & 19 & 1.0 & \\
\hline $1-3$ & 119 & 4.3 & 0.000078 \\
\hline$>3$ & 58 & 7.4 & \\
\hline \multicolumn{4}{|l|}{ Tumour size $(\mathrm{mm})^{a}$} \\
\hline$\leq 20$ & 89 & 1.0 & \\
\hline $21-30$ & 62 & 1.5 & 0.0031 \\
\hline$>30$ & 45 & 2.7 & \\
\hline \multicolumn{4}{|l|}{$A k t^{b}$} \\
\hline Akt- & 107 & 1.0 & \\
\hline Akt+ & 78 & 0.53 & 0.038 \\
\hline \multicolumn{4}{|c|}{ Radiotherapy/chemotherapyb } \\
\hline Radiotherapy & 86 & 1.0 & \\
\hline CMF chemotherapy & y 110 & 0.91 & 0.65 \\
\hline \multicolumn{4}{|l|}{ Tamoxifen ${ }^{b}$} \\
\hline No tamoxifen & 100 & 1.0 & \\
\hline Tamoxifen & 96 & 0.40 & 0.0010 \\
\hline \multicolumn{4}{|l|}{ Akt $\times$ tamoxifen } \\
\hline 0 & 147 & 1.0 & \\
\hline 1 & 38 & 1.7 & 0.28 \\
\hline
\end{tabular}

CMF, cyclophosphamide-methotrexate-5-fluorouracil.

a The variable was coded $0,1,2$.

b The variable was coded 0,1 .

\section{The benefit from chemotherapy versus radiotherapy in relation to Akt and erbB2}

The distant recurrence-free survival was similar for patients assigned to adjuvant CMF chemotherapy and to postoperative radiotherapy $(\mathrm{RR}=1.01 ; 95 \% \quad \mathrm{Cl}$, $0.71-1.42)$. The same was true in subgroups of patients divided by Akt or erbB2 status (data not shown).

Postoperative radiotherapy is known to have a significant protective effect upon locoregional relapse. In the present study the irradiated patients had a significantly reduced risk of locoregional recurrence compared with those receiving chemotherapy $(\mathrm{RR}=0.38 ; 95 \% \mathrm{Cl}, 0.20-0.75$; $P=0.0027)$. As shown in Figure 3 , the benefit from radiotherapy was higher in Akt-negative patients $(R R=0.23$; 95\% Cl, 0.08-0.67) compared with Akt-positive patients $(\mathrm{RR}=0.77 ; 95 \% \mathrm{Cl}, 0.31-1.9)$. The interaction between Akt and treatment was statistically significant when
Figure 3
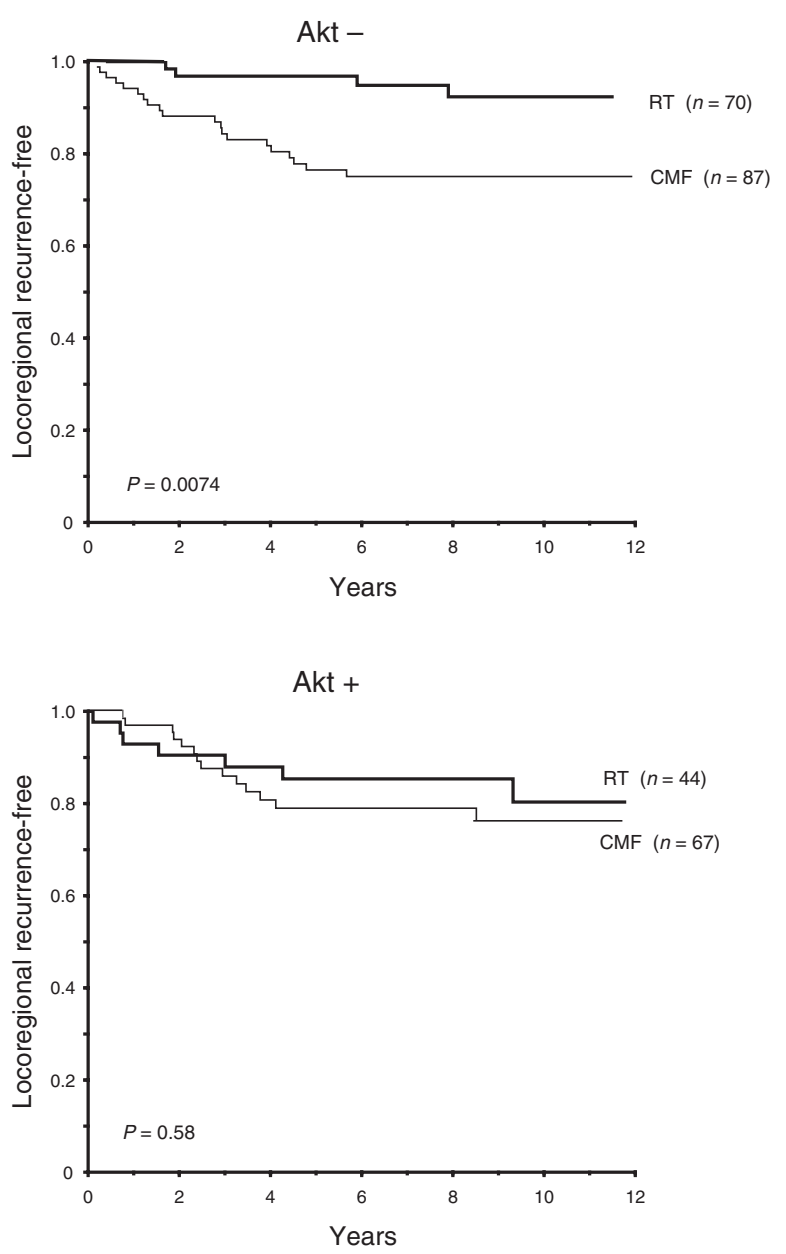

Locoregional recurrence-free probability for patients treated with postoperative radiotherapy (RT) or cyclophosphamide-methotrexate5-fluorouracil (CMF) chemotherapy in relation to Akt status.

analysed together with other variables $(P=0.042$; Table 5). Similarly, there was a difference in the efficacy of radiotherapy versus CMF comparing erbB2-negative patients and erbB2-positive patients $(\mathrm{RR}=0.25 ; 95 \% \mathrm{Cl}$, $0.10-0.65$ and $\mathrm{RR}=0.78 ; 95 \% \mathrm{Cl}, 0.29-2.1$, respectively). The interaction between erbB2 and treatment did not reach statistical significance in a multivariate model, where Akt was replaced by erbB2 $(P=0.095)$.

\section{Discussion}

During the past few years the association between Akt and cancer has become evident. One of the major functions of Akt is to promote growth-factor-mediated cell survival and to block apoptosis. The importance of Akt is demonstrated by the wide range of tissues in which the antiapoptotic activity has been shown. We observed staining for Akt1 in epithelial cells along the basement membrane. Activation of Akt suppresses anoikis, a process 
Table 5

\begin{tabular}{|c|c|c|c|}
\hline & $\begin{array}{l}\text { Number } \\
\text { of patients }\end{array}$ & $\begin{array}{l}\text { Rate } \\
\text { ratio }\end{array}$ & $\begin{array}{c}\text { Test for } \\
\text { significance }(P)\end{array}$ \\
\hline \multicolumn{4}{|c|}{ Number of positive nodes ${ }^{a}$} \\
\hline 0 & 32 & 1.0 & \\
\hline $1-3$ & 149 & 16.8 & 0.000008 \\
\hline$>3$ & 84 & 31.1 & \\
\hline \multicolumn{4}{|l|}{ Tumour size $(\mathrm{mm})^{a}$} \\
\hline$\leq 20$ & 111 & 1.0 & \\
\hline $21-30$ & 78 & 2.6 & 0.00031 \\
\hline$>30$ & 76 & 5.7 & \\
\hline \multicolumn{4}{|l|}{ ER status ${ }^{b}$} \\
\hline ER- & 78 & 1.0 & \\
\hline ER+ & 187 & 0.56 & 0.060 \\
\hline \multicolumn{4}{|l|}{$A k t^{b}$} \\
\hline Akt- & 155 & 1.0 & \\
\hline Akt+ & 110 & 0.71 & 0.33 \\
\hline \multicolumn{4}{|l|}{ Tamoxifen $^{b}$} \\
\hline No tamoxifen & 132 & 1.0 & \\
\hline Tamoxifen & 133 & 0.65 & 0.17 \\
\hline \multicolumn{4}{|c|}{ Radiotherapy/chemotherapyb } \\
\hline CMF chemotherapy & y 152 & 1.0 & \\
\hline Radiotherapy & 113 & 0.22 & 0.0065 \\
\hline \multicolumn{4}{|l|}{ Akt $\times$ radiotherapy } \\
\hline 0 & 221 & 1.0 & \\
\hline 1 & 44 & 4.3 & 0.042 \\
\hline
\end{tabular}

CMF, cyclophosphamide-methotrexate-5-fluorouracil.

a The variable was coded $0,1,2$.

b The variable was coded 0,1 .

when apoptosis is induced by disruption of the interaction between epithelial cells and the extracellular matrix $[32,33]$. Cancer cells have the capability to survive although they are detached from their normal structures, and activation of Akt may play a role in this process.

Some cell lines that overexpress erbB2 have shown high levels of Akt1 [34], and we hypothesised that there might be a correlation between erbB2 and Akt expression in breast tumours. We found a significant correlation between erbB2 and pAkt, whereas a correlation between erbB2 and Akt expression was found only for tumours that coexpressed Akt1 and Akt2. Bacus et al. [35] recently bly, erbB2 overexpression is implicated in the activation of both Akt1 and Akt2, in keeping with the fact that positive staining for pAkt may reflect phosphorylation of either of the isoforms. We previously found a correlation between stromal expression of heregulin $\beta 1$ and phosphorylated Akt in the malignant cells, further supporting a role of erbB2/erbB3 signalling for activation of Akt [36].

Amplification or increased activation of Akt2 is a relatively common event in ovarian cancer, particularly in advanced stages [7,24]. Gene amplification of Akt2 was found in $3 \%$ of the tumours in a breast cancer study [24], a figure that corresponds well to the number of cases with the highest score for Akt2 in the present study (Table 2). We found staining for Akt2 more frequently in ER-negative tumours. In contrast, Akt1 was expressed with similar frequencies in ER-positive tumours and in ER-negative tumours. Akt1 is expressed to various degrees in breast cancer cell lines and has been shown to be important in oestrogen-stimulated growth [34]. This was recently suggested also to be true for Akt2 [37]. Akt3 has not been extensively studied in human cancer, although a high expression level was associated with ER-negative breast cancer in one study [38]. Inhibition of the PI3-K/Akt pathway counteracts the accumulation of cyclin $D_{1}$ that normally is required for the $G_{1} / S$ transition following oestrogen stimulation [39].

The patients in the present study were randomised to adjuvant tamoxifen or to no endocrine treatment. The benefit from tamoxifen, in terms of an improved distant recurrencefree survival, was confined to ER-positive patients. Further analysis of ER-positive patients suggested that the benefit might also be related to Akt status (Fig. 2). However, this result is not really conclusive because the interaction between Akt and the effect of tamoxifen was not significant. This may be because of low statistical power or, alternatively, because other factors are more important for the prediction of tamoxifen therapy. However, it was recently shown that both PI3-K and Akt are capable of phosphorylating the ER at the activation function-1 site $[37,40]$, and inhibition of Akt increased tamoxifen-induced apoptosis [40]. Moreover, tamoxifen may induce transforming growth factor $\beta 1$ expression, and transforming growth factor $\beta 1$-induced apoptosis is suppressed through the same pathway [41]. Furthermore, in a study of premenopausal patients, who all received endocrine treatment, we found pAkt to predict a worse outcome [36].

We defined Akt-positive patients as those showing strong staining with at least one of the different Akt antibodies. In part this was made to gain statistical power, but it may also be motivated from a biological point of view. The downstream targets relevant to cancer development are probably shared by the different Akt kinases [42]. Furthermore, some cells with activated Akt may not be recog- 
nised by the antibody against the phosporylated serine residue at position 473 , as this is not the only phosporylation site of Akt.

In a previous study of 5 years versus 2 years of tamoxifen treatment, we found a decreased benefit from prolonged treatment in relation to erbB2 overexpression [29]. The erbB2 status failed to be predictive in the present study, which is similar to the results presented by Berry et al. [43]. In both these studies tamoxifen was given in addition to chemotherapy, which makes the interaction between erbB2 and treatment more complicated. However, too small a number of ER+/erbB2+ patients may be another reason for the lack of statistical significance.

Some experimental studies have found an interaction between the activity of Akt and the response to cytotoxic agents. Ovarian cancer cells overexpressing Akt were more resistant to paclitaxel than cancer cells expressing low Akt levels [6]. Inhibitors of PI3-K were found to increase apoptosis induced by UV treatment and hypoxia in breast cancer cells overexpressing erbB2 [35]. Decreased response to different cytotoxic drugs and gamma irradiation was reported in human glioblastoma cells after treatment with the multifunctional growth factor scatter factor/hepatocyte growth factor, which activates the PI3-K/Akt pathway [44]. Activation of Akt by scatter factor/hepatocyte growth factor not only inhibited apoptosis after DNA damage, but also activated DNA repair [45]. Altiok et al. [46] showed that the multifunctional BRCA1 protein, which is implicated in DNA repair, is phosphorylated by Akt after treatment with heregulin.

In line with these findings, Akt-positive patients showed decreased benefit from radiotherapy as concerns the locoregional control in the present study. Likewise, the efficacy of radiotherapy tended to be decreased for erbB2-positive patients. Node-positive patients treated with radiotherapy showed an increased risk of locoregional recurrence in relation to erbB2 overexpression in a previous study [28]. In the present study, none of the factors investigated showed any interaction with the effect of CMF chemotherapy versus radiotherapy for distant metastasis. Probably, the overall benefit from CMF was moderate in this series of postmenopausal women, as the rate of distant recurrence was similar in the chemotherapy and radiotherapy group.

The results of the present study do not indicate Akt as a pure prognostic factor, but rather it may be of importance for predicting the treatment effect. It is evident from the survival curves as well as from the multivariate analyses (Tables 4 and 5) that a positive Akt status was not associated with a worse outcome among patients not receiving tamoxifen or, in terms of locoregional recurrence, among patients not receiving radiotherapy.

\section{Conclusion}

This is the first study of Akt in a randomised material of breast cancer. We conclude that activation of Akt is correlated with erbB2 overexpression and with decreased local control benefit from radiotherapy. Further studies are needed to confirm this and also to prove whether the $\mathrm{PI} 3-\mathrm{K} /$ Akt pathway is important for the result of endocrine treatment. If so, this pathway should be an interesting target for new drugs.

\section{Acknowledgement}

This work was supported by grants from the Swedish Cancer Society.

\section{Competing interests}

None declared.

\section{Referencess}

1. Early Breast Cancer Trialists' Collaborative Group: Tamoxifen for early breast cancer: an overview of the randomised trials. Lancet 1998, 351:1451-1467.

2. Zhang $X$, Yee D: Tyrosine kinase signalling in breast cancer: insulin-like growth factors and their receptors in breast cancer. Breast Cancer Res 2000, 2:170-175.

3. Stern DF: Tyrosine kinase signalling in breast cancer: erbB family receptor tyrosine kinases. Breast Cancer Res 2000, 2:176-183.

4. Révillion F, Bonneterre J, Peyrat JP: ERBB2 oncogene in human breast cancer and its clinical significance. Eur J Cancer 1997, 34:791-808.

5. Kandel ES, Hay N: The regulation and activities of the multifunctional serine/threonine kinase Akt/PKB. Exp Cell Res 1999, 253:210-229.

6. Page C, Lin HJ, Jin Y, Castle VP, Nunez G, Huang M, Lin J: Overexpression of Akt/AKT can modulate chemotherapy-induced apoptosis. Anticancer Res 2000, 20:407-416.

7. Yuan ZQ, Sun M, Feldman RI, Wang G, Ma X, Jiang C, Coppola D, Nicosia SV, Cheng JQ: Frequent activation of AKT2 and induction of apoptosis by inhibition of phosphoinositide-3-OH kinase/Akt pathway in human ovarian cancer. Oncogene 2000, 19:2324-2330.

8. Brognard J, Clark AS, Ni Y, Dennis PA: Akt/protein kinase B is constitutively active in non-small cell lung cancer cells and promotes cellular survival and resistance to chemotherapy and radiation. Cancer Res 2001, 61:3986-3997.

9. Dudek H, Datta SR, Franke TF, Birnbaum MJ, Yao R, Cooper GM, Segal RA, Kaplan DR, Greenberg ME: Regulation of neuronal survival by the serine-threonine protein kinase Akt. Science 1997, 275:661-665.

10. Kauffmann-Zeh $A$, Rodriguez-Viciana $P$, Ulrich $E$, Gilbert $C$, Coffer P, Downward J, Evan G: Suppression of c-Myc-induced apoptosis by Ras signalling through $\mathrm{PI}(3) \mathrm{K}$ and PKB. Nature 1997, 385:544-548.

11. Kulik G, Klippel A, Weber MJ: Antiapoptotic signalling by the insulin-like growth factor I receptor, phosphatidylinositol 3kinase, and Akt. Mol Cell Biol 1997, 17:1595-1606.

12. Datta SR, Dudek H, Tao X, Masters S, Fu H, Gotoh Y, Greenberg ME: Akt phosphorylation of BAD couples survival signals to the cell-intrinsic death machinery. Cell 1997, 91:231-241.

13. del Peso L, Gonzalez-Carcia M, Page C, Herrera R, Nunez G: Interleukin-3-induced phosphorylation of BAD through the protein kinase Akt. Science 1997, 278:687-689.

14. Kennedy SG, Kandel ES, Cross TK, Hay N: Akt/protein kinase B inhibits cell death by preventing the release of cytochrome $\mathrm{C}$ from mitochondria. Mol Cell Biol 1999, 19:5800-5810.

15. Cantley LC, Neel BG: New insights into tumour suppression: PTEN suppresses tumour formation by restraining the phosphoinositide 3-kinase/AKT pathway. Proc Natl Acad Sci USA 1999, 96:4240-4245.

16. Lu Y, Lin YZ, LaPushin R, Cuevas B, Fang X, Yu SX, Davies MA Khan H, Furui T, Mao M, Zinner R, Hung MC, Steck P, Siminovitch K, Mills GB: The PTEN/MMAC1/TEP tumour suppressor gene 
decreases cell growth and induces apoptosis and anoikis in breast cancer cells. Oncogene 1999, 18:7034-7045.

17. Weng LP, Smith WM, Dahia PL, Ziebold U, Gil E, Lees JA, Eng C: PTEN suppresses breast cancer cell growth by phosphatase activity-dependent G1 arrest followed by cell death. Cancer Res 1999, 59:5808-5814.

18. Stambolic V, Tsao MS, Macpherson D, Suzuki A, Chapman WB, Mak TW: High incidence of breast and endometrial neoplasia resembling human Cowden syndrome in pten $+/-$ mice. Cancer Res 2000, 60:3605-3611.

19. Jones PF, Jakubowicz T, Hemmings BA: Molecular cloning of a second form of rac protein kinase. Cell Regulat 1991, 2:10011009.

20. Altomare DA, Guo K, Cheng JQ, Sonoda G, Walsh K, Testa JR: Cloning, chromosomal localization and expression analysis of the mouse Akt2 oncogene. Oncogene 1995, 11:1055-1060.

21. Nakatani K, Sakaue H, Thompson DA, Weigel RJ, Roth RA: Identification of a human Akt3 (protein kinase B $\gamma$ ) which contains the regulatory serine phosphorylation site. Biochem Biophys Res Commun 1999, 257:906-910.

22. Altomare DA, Lyons GE, Mitsuuchi Y, Cheng JQ, Testa JR: Akt2 mRNA is highly expressed in embryonic brown fat and the AKT2 kinase is activated by insulin. Oncogene 1998, 16:24072411.

23. Cheng JQ, Godwin AK, Bellacosa A, Taguchi T, Franke TF, Hamilton TC, Tsichlis PN, Testa JR: AKT2, a putative oncogene encoding a member of a subfamily of protein-serine/threonine kinases, is amplified in human ovarian carcinomas. Proc Natl Acad Sci USA 1992, 89:9267-9271.

24. Bellacosa A, de Feo D, Godwin AK, Bell DW, Cheng JQ, Altomare DA, Wan M, Dubeau L, Scambia G, Masciullo V, Ferrandina G, Benedetti Panici P, Mancuso S, Neri G, Testa JR: Molecular alterations of the AKT2 oncogene in ovarian and breast carcinomas. Int J Cancer 1995, 64:280-285.

25. Ruggeri BA, Huang L, Wood M, Cheng JQ, Testa JR: Amplification and overexpression of the AKT2 oncogene in a subset of human pancreatic ductal adenocarcinomas. Mol Carcinogen 1998, 21:81-86.

26. Rutqvist LE, Cedermark $B$, Glas $U$, Johansson $H$, Rotstein $S$, Skoog L, Somell A, Theve T, Askergren J, Friberg S, Bergström J, Blomstedt B, Räf L, Slifversvärd C, Einhorn J: Radiotherapy, chemotherapy, and tamoxifen as adjuncts to surgery in early breast cancer: a summary of three randomised trials. Int $J$ Radiat Oncol Biol Phys 1989, 16:629-639.

27. Stål O, Sullivan S, Sun X-F, Wingren S, Nordenskjold B: Simultaneous analysis of c-erbB-2 expression and DNA content in breast cancer using flow cytometry. Cytometry 1994, 16:160168.

28. Stål $\mathrm{O}$, Klintenberg $\mathrm{C}$, Sullivan $\mathrm{S}$, and the Southeast Sweden Breast Cancer Group: Overexpression of c-erbB-2 protein and locoregional recurrence in node-positive breast cancer. Breast 1997, 6:354-360.

29. Stål O, Borg $\AA$, Fernö M, Källström A-C, Malmström P, Nordenskjöld $B$, and members of the South Sweden Breast Cancer Group and the Southeast Sweden Breast Cancer Group: erbB2 status and the benefit from two or five years of adjuvant tamoxifen in postmenopausal early stage breast cancer. Ann Oncol 2000, 11:1545-1550.

30. Cox DR: Regression models and life tables. $J R$ Stat Soc $B$ 1972, 34:187-220.

31. Kaplan M, Meier P: Nonparametric estimation from incomplete observations. J Am Stat Assoc 1958, 53:457-481.

32. Attwell S, Roskelley C, Dedhar S: The integrin-linked kinase (ILK) suppresses anoikis. Oncogene 2000, 19:3811-3815.

33. Rytomaa M, Lehmann K, Downward J: Matrix detachment induces caspase-dependent cytochrome c release from mitochondria: inhibition by PKB/Akt but not Raf signalling. Oncogene 2000, 19:4461-4468.

34. Ahmad S, Singh N, Glazer RI: Role of AKT1 in 17ß-estradioland insulin-like growth factor I (IGF-I)-dependent proliferation and prevention of apoptosis in MCF-7 breast carcinoma cells. Biochem Pharmacol 1999, 58:425-430.

35. Bacus SS, Altomare DA, Lyass L, Chin DM, Farrell MP, Gurova K, Gudkov A, Testa JR: AKT2 is frequently upregulated in HER2/neu-positive breast cancers and may contribute to tumor aggressiveness by enhancing cell survival. Oncogene 2002, 21:3532-3540.
36. Pérez-Tenorio G, Stål O, and members of the Southeast Sweden Breast Cancer Group: Activation of AKT/PKB in breast cancer predicts a worse outcome among endocrine treated patients. Br J Cancer 2002, 86:540-545.

37. Sun M, Paciga JE, Feldman RI, Yuan Z, Coppola D, Lu YY, Shelley SA, Nicosio SV, Cheng JQ: Phosphatidylinositol-3-OH kinase (PI3K)/AKT2, activated in breast cancer, regulates and is induced by estrogen receptor $\alpha(E r \alpha)$ via interaction between $\mathrm{ER} \alpha$ and PI3K. Cancer Res 2001, 61:5985-5991.

38. Nakatani K, Thompson DA, Barthel A, Sakaue H, Liu W, Weigel RJ, Roth RA: Up-regulation of Akt3 in estrogen receptor-deficient breast cancers and androgen-independent prostate cancer lines. J Biol Chem 1999, 274:21528-21532.

39. Lobenhofer EK, Huper G, Iglehart JD, Marks JR: Inhibition of mitogen-activated protein kinase and phosphatidylinositol 3kinase activity in MCF-7 cells prevents oestrogen-induced mitogenesis. Cell Growth Differ 2000, 11:99-110.

40. Campbell RA, Bhat-Nakshatri P, Patel NM, Constantinidou D, Ali $\mathrm{S}$, Nakshatri H: Phosphatidylinositol 3-kinase/AKT-mediated activation of oestrogen receptor alpha: a new model for antioestrogen resistance. J Biol Chem 2001, 276:9817-9824.

41. Chen RH, Su YH, Chuang RL, Chang TY: Suppression of transforming growth factor-beta-induced apoptosis through a phosphatidylinositol 3-kinase/Akt-dependent pathway. Oncogene 1998, 17:1959-1968.

42. Mende I, Malstrom S, Tsichlis PN, Vogt PK, Aoki M: Oncogenic transformation induced by membrane-targeted Akt2 and Akt3. Oncogene 2001, 20:4419-4423.

43. Berry DA, Muss HB, Thor AD, Dressler L, Liu ET, Broadwater G, Budman DR, Henderson IC, Barcos M, Hayes D, Norton L: HER$2 /$ neu and p53 expression versus tamoxifen resistance in oestrogen receptor-positive, node-positive breast cancer. $J$ Clin Oncol 2000, 18:3471-3479.

44. Bowers DC, Fan S, Walter KA, Abounader R, Williams JA, Rosen $\mathrm{EM}$, Laterra J: Scatter factor/hepatocyte growth factor protects against cytotoxic death in human glioblastoma via phosphatidylinositol 3-kinase- and AKT-dependent pathways. Cancer Res 2000, 60:4277-4283.

45. Fan S, Ma YX, Wang JA, Yuan RQ, Meng O, Cao Y, Laterra JJ, Goldberg ID, Rosen EM: The cytokine hepatocyte growth factor/scatter factor inhibits apoptosis and enhances DNA repair by a common mechanism involving signalling through phosphatidyl inositol 3' kinase. Oncogene 2000, 19:22122223.

46. Altiok S, Batt D, Altiok N, Papautsky A, Downward J, Roberts TM, Avraham $\mathrm{H}$ : Heregulin induces phosphorylation of BRCA1 through phosphatidylinositol 3-kinase/AKT in breast cancer cells. J Biol Chem 1999, 274:32274-32278.

\section{Correspondence}

Olle Stål, PhD, Division of Oncology, University Hospital, SE-581 85 Linköping, Sweden. Tel: +46 13 223491; fax: +46 13 222846; e-mail: olle.stal@onk.liu.se 